\title{
Estimating seasonal abundance trends and survival probabilities of humpback whales in Hervey Bay (east coast Australia)
}

\author{
Milani Chaloupka ${ }^{1, *}$, Michael Osmond ${ }^{2}$, Greg Kaufman ${ }^{2}$ \\ ${ }^{1}$ Queensland Environmental Protection Agency, PO Box 155, Brisbane Albert Street, Queensland 4002, Australia \\ ${ }^{2}$ Pacific Whale Foundation, 101 North Kihei Road, Kihei, Hawaii 96753, USA
}

\begin{abstract}
The abundance of east Australian Group $V$ substock (EAGVS) humpback whales resident during winter in Hervey Bay was estimated from a 10 yr mark-resight study using photo-identification of 969 individual humpbacks sighted between 1987 and 1996. Hervey Bay is on the east coast of Australia and is the major southbound stop-over site for humpbacks returning to Antarctic waters from overwintering in Great Barrier Reef (GBR) waters. Seasonal abundance estimates were derived from mark-resight profiles using a reduced form Cormack-Jolly-Seber (CJS) model (constant survival, timevarying resight likelihood) that fitted the data well. The bootstrap mean CJS abundance estimate over the 9 yr period from 1988 to 1996 was 855 (95\% CI: 750 to 936). Estimated humpback abundance in Hervey Bay showed significant temporal variability superimposed on an increasing linear trend estimated using times series regression model bootstrapping at $6.3 \% \mathrm{yr}^{-1}(95 \% \mathrm{CI}: 2$ to $11 \%)$. The seasonal Hervey Bay population comprised 30 to $50 \%$ of the EAGVS southbound to Antarctic feeding grounds. Estimated abundance increased from 554 post-yearling humpbacks in 1988 to a peak of 1040 in 1991 before declining to 921 by the mid-1990s. Standard errors of abundance estimates suggested good precision and were derived using a variance components approach that separated sampling error from ecologically relevant variation. The trends in temporal variability and annual rate of humpback abundance increase were consistent with findings from an aerial surveillance study (1982 to 1996) of monthly sightings of the EAGVS overwintering in southern GBR waters. The concurrence of findings from an independent method of abundance estimation provides confidence in the CJS model used in this study to estimate abundance. Post-yearling survivorship was estimated from a 4 yr (1993 to 1996) photo-identification study of 517 individual humpbacks sighted at 2 seasonally sequential overwintering sites (Hervey Bay, Whitsundays) using a robust desion CJS modelling approach with estimators that account for bias due to temporary emigration. A reduced form CJS model (constant survival, timevarying resight likelihood) also fitted the data well with the mean annual survival rate for the EAGVS humpbacks estimated at 0.966 (95\% CI: 0.87 to 1.00 ). The good fit of the robust design survival rate model provides further confidence in the Hervey Bay abundance model, which suggests that the EAGVS has been recovering but at a slow and variable rate.
\end{abstract}

KEY WORDS: Humpback whales - Survivorship - Abundance estimation Mark-recapture - Robust design · Great Barrier Reef

\section{INTRODUCTION}

Humpback whales Megaptera novaeanghae migrate each year during the austral autumn along the east Australian coast from Antarctic summer feeding grounds to overwintering grounds in tropical waters (Kaufman

- Present address: Dept. of Zoology and Entomology, University of Queensland, St. Lucia, Queensland 4067, Australia. E-mail: m.chaloupka@mailbox.uq.edu.au et ai. 1990, 1993). This stock was severely reduced by commercial whaling during the 1950 s and early 1960 s (Chittleborough 1965). With the cessation of commercial whaling in 1963 this stock was estimated to have been less than $5 \%$ of its original size (Chittleborough 1965).

Despite severe depletion, the east Australian Group $V$ substock (EAGVS) of humpback whales has maintained its annual migration along the east Australian coast to overwintering grounds in Great Barrier Reef (GBR) waters (Kaufman et al. 1993, Chaloupka \& Os- 


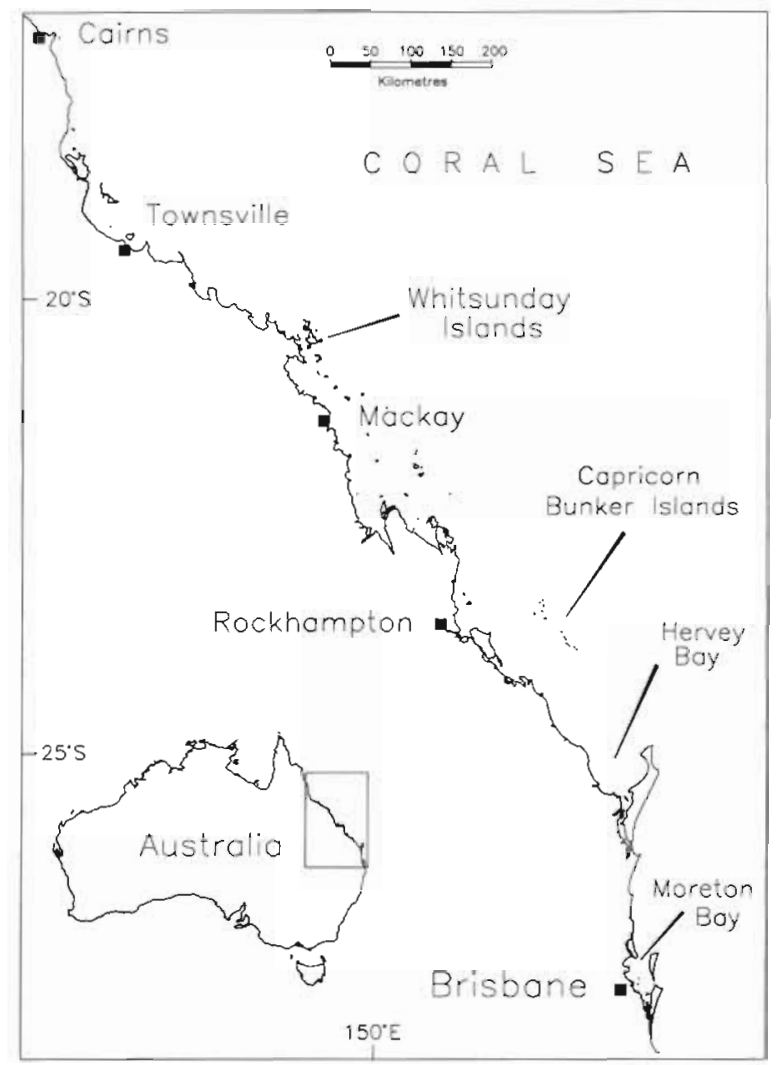

Fig. 1. Map showing the location of the Hervey Bay study area in southeastern Queensland (Australia) and the secondary sampling site in the Whitsunday Islands (southern Great Barrier Reef

mond 1999). The post-whaling recovery of the EAGVS has been documented in recent studies using shorebased observations in southern Queensland waters (Paterson et al. 1994) and aerial surveillance sightings in the GBR Marine Park (Chaloupka \& Osmond 1999).

During the southbound return migration to feeding grounds in Antarctic waters a proportion of the EAGVS humpbacks enter Hervey Bay in southern Queensland waters (Fig. 1). A major commercial whale-watching industry has developed recently in Hervey Bay and southern Queensland waters (Chaloupka 1990, 1996), creating a need for policies designed to ensure recovery of the EAGVS humpbacks. The development of management policies and recovery plans depends on a clear understanding of EAGVS population dynamics and reliable estimates of seasonal population abundance and overall Group V stock size.

The recent ability to identify individual whales through photographs of natural markings has provided the basis for long-term studies of humpback population dynamics (Baker et al. 1986, Clapham \& Mayo 1987, Katona \& Beard 1990, Kaufman et al. 1993). A major aim of such photo-identification studies is the estimation of population abundance and stock recovery rates using capture-recapture or mark-resight methods (Hammond 1986).

We present estimates of annual population abundance and long-term recovery rates for the EAGVS resident in Hervey Bay based on photo-identification of individual humpbacks sighted during the southbound migration between 1987 to 1996 . We also present survival probability estimates for the EAGVS humpbacks using a robust sampling design (Pollock et al. 1990) for photoidentification of whales at 2 overwintering sites and statistical estimators that account for potential parameter bias due to temporary emigration (Kendall et al. 1997).

\section{METHODS AND MATERIALS}

Study site. Hervey Bay is a large shallow marine embayment located in Queensland on the east coast of Australia (Fig. 1). It is bounded on the eastern side by Fraser Island, which protrudes across most of the continental shelf. In 1987 the Pacific Whale Foundation. (PWF) began a mark-resight study in eastern Hervey Bay using photo-identification of individual EAGVS humpbacks sighted between August and October (Kaufman et al. 1993). The program has been ongoing ever since with support from the Queensland Environmental Protection Agency (Kaufman et al. 1993). Studies using aerial surveys have shown that a random sample of the EAGVS humpbacks enter Hervey Bay during the southward migration only (August to October) and are concentrated in the eastern part of the Bay (Corkeron et al. 1994). The eastern portion of Hervey Bay was declared a marine park in 1989 with a management framework implemented for the regulated development of a commercial whale-watching industry (Chaloupka 1990).

Sampling approach. Depending on weather conditions, a PWF research team was deployed daily in Hervey Bay each season (August to October) from 1987 to 1996. Similar field sampling and photo-identification methods were used throughout the study with several of the field staff being involved for most of the $10 \mathrm{yr}$ study period. Humpback pods (mainly 1 to 10 individuals) were observed by a research team ( $\geq 2$ people) operating from a small outboard-driven vessel using a random search pattern. Hervey Bay is a large area (ca $4000 \mathrm{~km}^{2}$ ) but the seasonal concentration of humpbacks in the eastern portion of the Bay ensures a reasonable likelihood of sighting a whale that enters during the southbound migration. More details of the field methods can be found in Kaufman et al. (1987, 1993).

Individual identification. EAGVS humpbacks have individually identifiable patterns on the ventral side of the tail-flukes (Kaufman et al. 1993) Many EAGVS 
humpbacks (ca $57 \%$ ) also have a unique lateral body pigmentation pattern (Kaufman et al. 1987). Photographs were taken of the ventral surface of the tailfluke of each whale sighted. Where possible, photographs were also taken of the left and right lateral body pigmentation pattern for individual recognition (Kaufman et al. 1987) and of the genital area for sex determination (Glockner 1983). Each whale was photographed using a $35 \mathrm{~mm}$ single-lens reflex camera, equipped with a motor drive and either a $300 \mathrm{~mm}$ telephoto or an 80 to $200 \mathrm{~mm}$ zoom lens. The cameras were loaded with either Kodak 64 or 100 ASA colour slide film. A photo-identification catalogue was compiled using tail-fluke and lateral body pigmentation photographs that passed a standard quality acceptance test (Baker et al. 1986, Kaufman et al. 1993). The photo-identification catalogue enabled an annual resight history profile to be recorded for each of the 969 individual humpbacks sighted in Hervey Bay from 1987 to 1996.

Statistical modelling approach. Population abundance estimates of EAGVS humpbacks in Hervey Bay from 1987 to 1996 were derived using the annual resight histories for each of the 969 individually identified whales and the Cormack-Jolly-Seber (CJS) statistical modelling approach of Pollock et al. (1990). The standard CJS approach does not assume demographic closure and so is suitable for estimation of population parameters where there is an underlying stochastic birth, death and permanent emigration process between sampling periods. The statistical assumptions and limitations of the CJS modelling approach for estimation of population abundance and demographic probabilities were discussed in detail elsewhere (Pollock et al. 1990, Lebreton et al. 1992, Kendall et al. 1997). Hammond (1986) addresses some of these issues in relation to photo-identification-based mark-resight studies of whale population abundance.

The critical assumption of no temporary emigration is considered most likely to be violated in humpback demographic studies leading to biased estimates of abundance and survival probabilities (Buckland 1990). We evaluated this assumption in our study using the robust design extension to the standard CJS model (Pollock et al. 1990) coupled with modified estimators that account for bias due to the presence of temporary emigration (Kendall et al. 1997). The robust design in the current study used a photo-identification sampling program of EAGVS humpbacks $(n=517)$ resident in 2 overwintering locations (secondary samples) within each sampling year (primary samples). The primary samples spanned the 4 yr period from 1993 to 1996.

The 2 secondary sampling locations were the Whitsunday Islands (southern GBR; sGBR) and Hervey Bay (Fig. 1). The Whitsundays and sGBR lagoonal waters comprise the main calving and overwintering grounds for the EAGVS humpbacks (Chaloupka \& Osmond 1999). The Whitsunday Island program began in 1993 with sampling at the end of the northbound migration during June and July of each year prior to the research team relocating southward to Hervey Bay to continue sampling from August to October during the southbound migration (Fig. 1). The robust design used here assumed that the EAGVS being sampled each year comprised a single superpopulation (see Kendall et al. 1997) with demographic closure within a season during sequential sampling of the overwintering sites. Demographic closure was not assumed between primary sampling periods. The use of the robust design approach and modified CJS estimators provided not only an evaluation of the major assumption of no temporary emigration but also provided a robust estimate of the mean annual survival probability for postyearling EAGVS humpbacks.

\section{RESULTS}

\section{Mark-resight summary}

There were 969 individual humpback whales identified photographically in Hervey Bay over the $10 \mathrm{yr}$ sampling period between August 1987 and October 1996. All 969 resight history profiles used in the analysis were for post-yearlings, comprising 156 subadults and 813 adults. Calves were not included in the photoidentification study because of the potential for substantial change in the pigmentation patterning in the first year of postnatal development (Carlson et al. 1990). Sex was not considered because $<21 \%$ of the sample could be sexed and subadult males were 2 times more likely to be sexed than adult males due to frequent roll-over behaviour (odds ratio $=2.18,95 \%$ CI: 1.01 to 4.68 ; see Fleiss 1981). The resight history profiles comprised $70 \%$ of the 969 whales sighted once only between sampling years, $21 \%$ sighted twice and $9 \%$ sighted $\geq 3$ times. The mark-resight summary statistics for the 969 resight profiles required for CJS population abundance estimation are shown in Table 1.

\section{Initial goodness-of-fit tests}

The full CJS model (time-varying survival, timevarying resight) comprising separate parameter estimates for the subadult and adult subgroups fitted the data set extremely well with no evidence for noncompliance with the standard CJS model assumptions (TEST $2+3$ of Burnham et al. 1987 as modified recently by Pradel 1993 to account for heterogeneity of resight 
Table 1. Mark-resight summary statistics and Cormack-Jolly-Seber population estimates for adult/subadult east Australian Group V substock (EAGVS) humpbacks resident in Hervey Bay Marine Park during the annual southward migration. (1987 to 1996). $n_{i}$ : total number of adult/subadult humpbacks (marked + unmarked) sighted in $i$ th period, $m_{i}$ : number of marked humpbacks sighted in ith period, $R_{i}$ : number of $n_{1}$ released after ith period, $r_{j}$ : number of $R$, sighted in ith period and resighted in a subsequent period; $Z_{i}$ : number sighted before and after $i$ th period but not in $i$ th periodi $N_{i}$ : estimated population size of adult/subadult EAGVS at ith period; $\operatorname{SE}\left(N_{i}\right)=$ standard error of population estimate at $i$ th period including sampling error and temporal variability terms (Pollock et al. 1990), $\mathrm{SE}_{a d j}\left(N_{i}\right)=$ standard error of population estimate at ith period excluding sampling error (Link \& Nichols 1994). Annual adult/subadult population abundance estimates derived from a constant survival/time-

varying resight likelihood model (Model B; see Pollock et al. 1990). tse $_{i}$ : total sampling effort in boat-days in ith period

\begin{tabular}{|c|c|c|c|c|c|c|c|c|c|c|}
\hline Period & Year & $n_{1}$ & $m_{1}$ & $R_{i}$ & $r$ & $z_{i}$ & $N_{1}$ & $\operatorname{SE}\left(N_{i}\right)$ & $\mathrm{SE}_{\text {adij }}\left(N_{i}\right)$ & tse \\
\hline 1 & 1987 & 37 & & 37 & 23 & & & & & 32 \\
\hline 2 & 1988 & 227 & 13 & 227 & 97 & 10 & 554 & 115 & 91 & 59 \\
\hline 3 & 1989 & 190 & 54 & 190 & 75 & 53 & 712 & 65 & 52 & 31 \\
\hline 4 & 1990 & 104 & 35 & 104 & 34 & 93 & 847 & 95 & 75 & 30 \\
\hline 5 & 1991 & 125 & 35 & 125 & 46 & 92 & 1040 & 131 & 104 & 34 \\
\hline 6 & 1992 & 115 & 39 & 115 & 36 & 99 & 935 & 108 & 86 & 36 \\
\hline 7 & 1993 & 209 & 67 & 209 & 58 & 68 & 1004 & 103 & 82 & 48 \\
\hline 8 & 1994 & 169 & 79 & 169 & 33 & 47 & 816 & 75 & 60 & 57 \\
\hline 9 & 1995 & 83 & 40 & 83 & 7 & 40 & 830 & 93 & 74 & 16 \\
\hline 10 & 1996 & 119 & 47 & 119 & & & 921 & 118 & 94 & 22 \\
\hline
\end{tabular}

likelihood: $\chi^{2}$ o.05 $=75.8, \mathrm{df}=68, \mathrm{p}>0.20$ ). Moreover, there was no evidence with any significant difference in survival or resight likelihood between the subadult and adult groups (TEST 1 of Burnham et al. 1987: $\chi^{2} 0.05$ $=14.01, \mathrm{df}=17, \mathrm{p}>0.65)$. Hence, the subadult and adult subgroups were pooled into a data set of 969 resight profiles for the assessment of population abundance. Goodness-of-fit tests for mark-resight analyses are discussed in detail by Burnham et al. (1987), Lebreton et al. (1992) and Pradel (1993).

\section{Population abundance estimates}

Given that there was no evidence for noncompliance with the standard assumptions of the CJS model (including resight likelihood homogeneity), the full CJS model (time-varying survival, time-varying resight) and several reduced forms of the CJS model (Pollock et al. 1990) were then fit to the 969 resight profiles to estimate annual post-yearling population abundance. The best fit model of the family of models tested was the CJS reduced form Model B (Pollock et al. 1990), which assumes constant annual survival and time-varying resight likelihood. Seasonal resight likelihood was considered reasonable for such a markresight study with large population size (geometric mean resight likelihood $=0.168, \mathrm{CV}=15.6 \%$ ). It is particularly important to note that Model B fitted the data very well $\left(\chi_{0.05}^{2}=33.3, \mathrm{df}=29, \mathrm{p}>0.27\right)$ with no evidence for noncompliance with standard CJS model assumptions. There was also no significant difference in fit between the full CJS model and the reduced form Model B (log-likelihood ratio test: $\chi_{0.05}^{2}=5.2, \mathrm{df}=7, \mathrm{p}>$
$0.64)$. Model B was therefore selected as the preferred model since it not only fitted the data as well as the full CJS model but was simpler, requiring less model parameters. Model selection strategies for mark-resight analyses are discussed in detail by Burnham et al. (1995).

Model B (constant survival, time-varying resight) enables abundance estimates to be derived for $9 \mathrm{yr}$ (1988 to 1996) of the 10 yr study (1987 to 1996). If the full CJS model (time-varying survival, time-varying resight) had been the best fit, rather than a reduced form model such as Model $B$, then abundance estimates would have been only possible for 8 yr (1988 to 1995). The abundance estimates $\left(N_{1}\right)$ derived from Model B and the approximate standard errors ( $\mathrm{SE}\left[N_{i}\right]$ ) including non-sampling error terms are given in Table 1. Following the variance components approach of Link \& Nichols (1994) it was possible to distinguish between variability in abundance estimation due to (1) sampling uncertainty and (2) ecologically relevant variation $\left(\mathrm{SE}_{\text {adj }}\left[N_{i}\right]\right.$, Table 1$)$. Seasonal abundance estimates (1988 to 1996 ) and approximate $95 \%$ confidence curves are shown in Fig. $2 \mathrm{a}$ based on the $\left(\mathrm{SE}\left[N_{i}\right]\right)$ to reflect total variance since sampling uncertainty accounted for $<21 \%$ of the total variability in seasonal abundance. Standard errors of abundance estimates accounting for total variance suggested good precision (geometric mean $\mathrm{CV}=11.7 \%$ ).

\section{Sampling effort}

Annual sampling effort measured as boat-days on water in Hervey Bay varied considerably from 1.987 to 


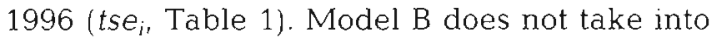
account sampling effort nor any other study covariates (Pollock et al. 1990). However, it can be shown graphically that annual abundance estimates derived from Model B (Table 1) were not a function of sampling effort (Fig. 3a) nor were the resight likelihood estimates a function of sampling effort (resight/recapture probability ranged from 0.10 to 0.41 , geometric mean = 0.168 , Fig. 3b). This was only a limited assessment of sampling effort, but more comprehensive modelling of stage-specific survival probabilities (subadult, adult) between 1987 and 1996 using the parametric modelling approach of Lebreton et al. (1992) found no linear or curvilinear functional relationship between either stage-specific survival or resight probability estimates and sampling effort for this same data set (Chaloupka \& Osmond unpubl.).

\section{Population recovery trend}

A linear regression model with log link and second order moving average error (MA2: see Judge et al. 1985) was used to estimate the long-term linear trend in humpback abundance over time (1988 to 1996) shown in Fig. 2a. The response variable (annual population estimate, Table 1) was in natural log form so that the parameter estimate for the independent variable (year: 1988 to 1996) was interpretable as proportional change or annual growth rate. The linear regression model with MA2 error fitted the data well (residual variance $=$ $0.014, \mathrm{R}^{2}=0.68, t$-ratio $[\mathrm{yr}]=3.14, \mathrm{df}=7, \mathrm{p}<0.01$ ) compared to a linear model with standard normal error (residual variance $=0.029, \mathrm{R}^{2}=0.32$, $t$-ratio $[\mathrm{yr}]=1.80, \mathrm{df}=7, \mathrm{p}>0.05)$, confirming that accounting for autocorrelated error in parameter estimation was needed.

Robust parameter estimation and statistical inference for the MA2 model was then derived from 1000 bootstrap samples (Efron \& Tibshirani 1986) of the residuals drawn from the initial MA2 model with a median estimator (50th empirical percentile) and $95 \%$ confidence intervals defined by the 2.5 th and 97.5 th empirical percentiles of the bootstrap distribution for each parameter. The MA2 model was a good fit to the data, supporting use of a bootstrapping residuals approach rather than a bootstrapping pairs approach (Efron \& Tibshirani 1986). Moreover, the bootstrap distributions for each parameter estimate $(n=1000)$ were asymmetric, supporting use of a nonparametric bootstrapping procedure for deriving less biased parameter estimates and for statistical inference. Given this
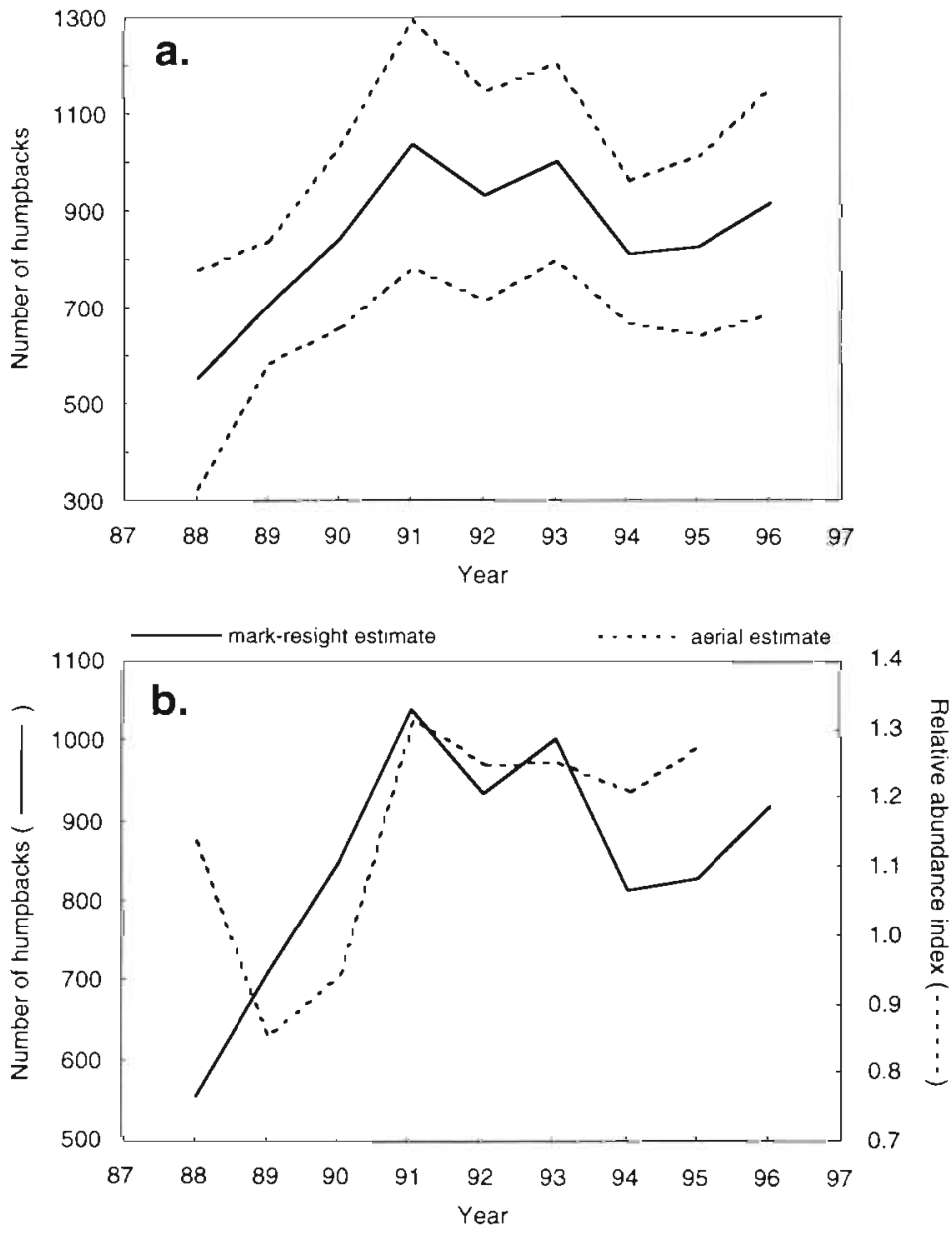

Fig. 2. Megaptera novaeangliae. Population abundance estimates for the east Australian Group V substock (EAGVS) humpbacks that overwinter each year in Queensland waters. (a) Estimated annual abundance of EAGVS humpbacks resident seasonally in Hervey Bay from 1988 to 1996. (-) mean annual population estimate. (---) pointwise $95 \%$ confidence curves around the annual estimate. (b) Comparison of the estimated annual abundance of EAGVS humpbacks resident seasonally in Hervey Bay from 1988 to 1996 (-) and the estimated relative abundance of EAGVS humpbacks in

the nearby Great Barrier Reef region for the same period (----)

approach, it was estimated that the Hervey Bay humpback population trend shown in Fig. 2a has increased since 1987 at a median annual growth rate of ca $6.3 \%$ $\mathrm{yr}^{-1}\left(95 \% \mathrm{CI}: 2\right.$ to $\left.11 \% \mathrm{yr}^{-1}\right)$.

\section{Survival probability estimate}

The full robust design CJS model (time-varying survival, time-varying resight; Kendall et al. 1997) and several reduced model forms were fit to the 517 resight profiles for the 2 overwintering sites (Whitsunday Islands and Hervey Bay: see Fig. 1) sampled concurrently between 1993 and 1996. The best fit model of 

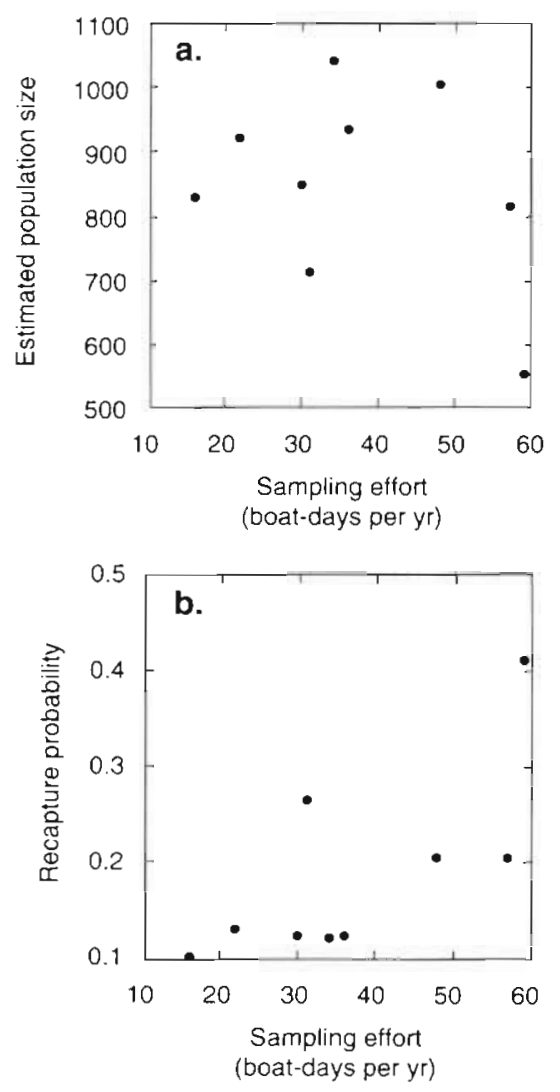

Fig. 3. Megaptera novaeangliae. Relationship between annual sampling effort in Hervey Bay (boat days $\mathrm{yr}^{-1}$ ) and (a) estimated annual EAGVS humpback abundance in Hervey Bay (1988 to 1996, Table 1) and (b) estimated resight or recapture probability (1988 to 1996) derived from Model B (constant survival, time-varying resight)

the family of models tested was Model 2 shown in Table $2\left(\chi_{0.05}^{2}=21.8, \mathrm{df}=17, \mathrm{p}>0.19\right.$, Akaike Information Criterion $[\mathrm{AIC}]=124.9$ ), which assumes constant survival, time-varying resight and permanent emigra- tion. It is important to note that Model 2 (Table 2) is a very good fit to the data. There was no evidence for the presence of any significant between-season temporary emigration using the 2-site sequential seasonal sampling design adopted during this 4 yr study (1993 to 1996) - compare Models 4 and 5 with Model 2 in Table 2. Burnham et al. (1995) discuss the use of AIC for CJS model selection and goodness-of-fit testing (see also Lebreton et al. 1992).

Model 2 is equivalent in terms of the survival, resight likelihood and emigration assumptions to the Pollock et al. (1990) Model B used in this study to derive annual abundance estimates for the Hervey Bay humpback population (Table 1). The mean annual survival rate for post-yearling EAGVS humpbacks estimated from Model 2 in Table 2 was 0.966 (95\% CI: 0.87 to 1.00 ). The asymmetric confidence interval results from the recommended lognormal-transformation with 10,1$]$ constraint (Lebreton et al. 1992).

\section{DISCUSSION}

\section{Sampling issues}

Four key sampling issues need to be considered to support confidence in the abundance estimates (Table 1) for post-yearling humpbacks derived from the mark-resight study using photo-identification (1) reliability of individual recognition, (2) stock definition, (3) adequacy of seasonal and spatial sampling effort, and (4) demographic representativeness.

The use of natural markings to support a photoidentification-based mark-resight study is widely accepted for humpback populations (Baker et al. 1986, Hammond 1986, Clapham \& Mayo 1987, Buckland 1990, Katona \& Beard 1990, Kaufman et al. 1993, Craig \& Herman 1997). EAGVS humpbacks

Table 2. Survivorship modelling summary for the adult/subadult EAGVS humpbacks at 2 overwintering sites (Whitsunday Islands, Hervey Bay) based on Pollock's robust design for capture-recapture type data (Pollock et al. 1990) and accounting for potential temporary emigration (see Kendall et al. 1997). Robust design comprises 2 secondary samples (Whitsundays, Hervey Bay) each year within 4 primary (1993 to 1996) annual sampling periods. Model descriptions given in Lebreton et al. (1992) notation with Kendall et al. (1997) extensions for temporary emigration. GoF: goodness-of -fit tests; df: degrees of freedom; dev: relative deviance; AIC: Akaike Information Criterion (see Burnham et al. 1995). Model 3 is the standard Cormack-Jolly-Seber model. Best fit model shown by lowest AIC value (Model 2) and is equivalent to the Pollock et al. (1990) Model B used in the current study to estimate annual adult/subadult EAGVS population size from 1988 to 1996 (see Table 1)

\begin{tabular}{|c|c|c|c|c|c|c|c|c|}
\hline \multirow[b]{2}{*}{ No. } & \multicolumn{4}{|c|}{ Model description } & \multicolumn{2}{|c|}{ GoF } & \multirow[t]{2}{*}{ dev } & \multirow[t]{2}{*}{ AIC } \\
\hline & Survival rate $(\sigma)$ & Recapture rate $(\rho)$ & Emigration $(\gamma)$ & Notation & $\chi^{2}$ & $\mathrm{df}$ & & \\
\hline 1 & Constant & Constant & Permanent & $\sigma, \rho$ & 238.4 & 21 & 323.5 & 333.5 \\
\hline 2 & Constant & Time-varying & Permanent & $\sigma_{1} \rho_{t}$ & 21.8 & 17 & 106.9 & 124.9 \\
\hline 3 & Time-varying & Time-varying & Permanent & $\sigma_{t}, \rho_{r}$ & 20.9 & 15 & 105.9 & 127.9 \\
\hline 4 & Constant & Time-varying & Temporary & $\sigma_{1} p_{1}, \gamma_{\text {random }}$ & 20.9 & 14 & 105.9 & 129.9 \\
\hline 5 & Constant & Time-varying & Temporary & $\sigma, \rho_{\ell}, \gamma_{\text {markovian }}$ & 20.9 & 13 & 105.9 & 131.9 \\
\hline
\end{tabular}


have individually identifiable patterns on the ventral side of the tail flukes (Kaufman et al. 1990, 1993) and many have a unique lateral body pigmentation pattern (Kaufman et al. 1987). The current photo-identification study was based on tail-fluke identification supplemented by lateral body markings, where the latter was also recorded in addition to the tail-fluke identification. The use of these 2 natural marking schemes reduces the likelihood of mis-identification of those individual humpbacks that were effectively 'double-marked'.

The humpback stock that migrates annually between Antarctic Area $V$ feeding grounds and various southwestern Pacific overwintering grounds is known as the Group V stock (Chittleborough 1965). The annual movement of Group $V$ humpbacks between Antarctic Area $V$ feeding grounds and east Australian coastal waters is well known from whaling records (Chittleborough 1965) and mark-resight studies based on photo-identification of individual humpbacks (Kaufman et al. 1990). We refer to the Group V subset that migrates each year along the east Australian coast to overwinter in GBR waters as the EAGVS (Chaloupka \& Osmond 1999). The current study is based on EAGVS humpbacks that assemble for a. short period each year in Hervey Bay during the southbound migration. Mean residence time of EAGVS humpbacks in Hervey Bay is ca 1 to $3 \mathrm{~d}$ (Corkeron et al. 1994).

The seasonality of humpbacks in the overwintering grounds in southern GBR waters (Whitsunday Islands to Capricorn-Bunker Islands, Fig. 1) is known from a 14 yr study of aerial surveillance sightings (Chaloupka \& Osmond 1999). The historic seasonal peak for humpbacks in sGBR waters occurs in August with peak season in Hervey Bay occuring approximately 1 mo later during September (Corkeron et al. 1994). The current photo-identification study in Hervey Bay commenced sampling each year from early August to late October during the southbound migration to ensure adequate seasonal sampling. The predominance of whales in the eastern portion of Hervey Bay (Corkeron et al. 1994) reduced significantly the area that needed to be covered in order to locate whales in the sampling program. The sighting of humpbacks was also assisted by the commercial whale watching fleet that was in radio contact with the PWF research vessel. Annual sampling effort measured as boat-days on water in Hervey Bay varied considerably (Table 1), but recapture probability was adequate and not confounded with sampling effort (Fig. 3b).

The demographic segregation of migratory humpbacks based on age and sex classes is well documented (Chittleborough 1965). Such nonrandom migratory behaviour could lead to sampling bias if Hervey
Bay was also used disproportionately by a specific demographic group of the population on the southbound migration. There appears to be no demographic bias in the humpbacks sighted seasonally in Hervey Bay (Corkeron et al. 1994, authors' pers. obs.). Moreover, there appears to be no indication of population parameter bias due to either heterogeneity of resight (see 'Results: Initial goodness-of-fit tests') or the possible presence of temporary emigration between seasons during the 4 yr span from 1993 to 1996 (Table 2). It is reasonable then to assume that the post-yearling humpbacks sighted in Hervey Bay each season between 1987 and 1996 were a representative sample of the EAGVS population during the southbound migration.

\section{Population abundance}

While there are many estimates of seasonal humpback abundance for short-term studies (<5 yr) using individual photo-identification methods, there have been very few studies that have presented long-term (ca 10 yr) abundance estimates, which are considered essential for estimation of stock size and recovery trends (Hammond 1986). Buckland (1990) using a cohort-based CJS approach (Pollock et al. 1990) to account for sampling bias due to resight heterogeneity estimated that seasonal abundance of western North Atlantic stock (WNAS) humpbacks in the Gulf of Maine feeding ground increased over a $9 \mathrm{yr}$ period (1977 to 1985 ) from 99 (95\% CI: 40 to 160$)$ to 334 (95\% CI: 300 to 360 ). While no indication of model fit was provided, the small apparent population size and very high resight likelihood in this study resulted in good precision of seasonal abundance estimates. However, Buckland (1990) attributed the trend in seasonal abundance to be a direct function of the increasing likelihood of resight over the 10 yr study period, which was probably a consequence of a temporal trend in sampling effort.

Katona \& Beard (1990) estimated humpback abundance of the whole WNAS over an 8 yr period from 1979 and 1986 using a Lincoln-Petersen (LP) estimator that assumes demographic closure and constant resight likelihood. The annual abundance estimates displayed substantial inter-annual variability and comprised sightings pooled from many studies conducted in the breeding grounds and in the different feeding grounds with variable sampling effort and study duration. The estimated mean WNAS size between 1979 and 1986 was 5505 (95\% CI: 2900 to 8100). Using a similar LP estimator and genetic-marker identification of individual humpbacks sighted in the West Indies breeding grounds, Palsboll et al. (1997) estimated the total WNAS size in 1992 from a single year census as 
7698 (approximate 95\% CI: 5100 to 11500 based on summing the gender-specific estimates). The confidence interval ranges in these 2 WNAS assessments suggest poor estimation precision probably due to a combination of inadequate sampling effort and failure of the LP estimator assumptions of demographic closure and constant resight likelihood (see Buckland 1990). Nonetheless, these estimates are the only recent whole-of-stock assessment estimates available for any humpback stock.

We present estimates of the abundance of EAGVS humpbacks resident during the late winter in Hervey Bay over the 9 yr period from 1988 to 1996 using a reduced form CJS model that fitted the data well with no evidence for noncompliance with standard CJS model assumptions including resight homogeneity. The good fit of the robust design CJS survival probability model (Table 2) supports confidence in the reduced form CJS model used to estimate EAGVS seasonal abundance in Hervey Bay. These estimates were based on a $10 \mathrm{yr}$ mark-resight study using photo-identification of 969 individual humpbacks sighted in the Bay between 1987 and 1996 during the southbound migration to Antarctic waters. The estimated annual abundance of post-yearling humpbacks increased from 554 (95\% CI: 329 to 779 ) in 1988 to a peak of 1040 (95\% CI: 783 to 1297 ) in 1991 before declining to ca 921 (95\% CI: 690 to 1152 ) by the mid-1990s (see Fig. 2a).

It is important to note that these are estimates only of the seasonal abundance of EAGVS humpbacks in Hervey Bay (Table 1), which represent an unknown and probably variable proportion of the EAGVS population that migrates each year along the east Australian coast. There are no long-term annual abundance estimates for the EAGVS humpbacks migrating along the east Australian coast concurrent with the same Hervey Bay photo-identification study period (1988 to 1996), let alone any estimates of Group $V$ stock abundance. However, there are some point estimates of the EAGVS population size during this period.

For instance, using a shore-based observation study, Paterson et al. (1994) estimated the size of the EAGVS population passing Moreton Bay (Fig 1) in 1992 to comprise 1836 post-yearlings (95\% asymptotic normal CI: 1400 to 2392) compared to 1100 in 1987. The EAGVS population size in 1987 was estimated for the same location to be 1203 (95\% Monte Carlo CI: 1134 to 1273 ) based on a 4 yr photo-identification study and Cormack's (1993) Poisson likelihood modelling approach (Chaloupka 1996).

It was then estimated using a Monte Carlo simulation model that the EAGVS passing Moreton Bay in 1996 was ca 1928 post-yearlings ( $95 \%$ CI: 1645 to 2404 ), assuming that post-1987 population growth was a random variate sampled from an extreme value probability density function (mode $=5 \%$, scale $=0.01 \%$, range 3 to $11 \% \mathrm{yr}^{-1}$; Chaloupka 1996). This annual growth rate sampling distribution is consistent with estimates based on aerial surveillance of EAGVS humpback sightings in the GBR (1982 to 1996; Chaloupka \& Osmond 1999), the current study for the seasonal abundance of EAGVS humpbacks in Hervey Bay (1988 to 1996) and with estimates for other humpback stocks (Volgenau et al. 1995, Barlow \& Clapham 1997). Assuming that the EAGVS abundance estimates for 1992 (Paterson et al. 1994) and for 1996 (Chaloupka 1996) were reasonably accurate, then it was estimated that the seasonal abundance of humpbacks in Hervey Bay (Table 1) comprises ca 30 to $50 \%$ of the southbound EAGVS population that varies from season to season.

\section{Temporal variability}

Brown et al. (1995) suggested from a 1 yr biopsy sampling study of apparent sex ratios that a significant proportion of female EAGVS humpbacks in the Antarctic Area $V$ feeding grounds did not migrate in 1992 to east Australian coastal waters and might have remained in Antarctic waters during that winter. Elsewhere, Craig \& Herman (1997) have shown from a photo-identification study (1976 to 1991) that female North Pacific humpbacks were less likely to migrate in some years from high-latitude feeding grounds to Hawaiian breeding grounds compared to male humpbacks. Such sexspecific differences in migration likelihood will be evident in significant aperiodic variability in the seasonal abundance of humpbacks in the breeding grounds

The seasonal abundance in Hervey Bay between 1988 and 1996 was estimated with good precision (geometric mean $\mathrm{CV}=11.7 \%$ ) and displayed lowfrequency temporal variability (Fig 2a). It was estimated that the Hervey Bay population increased significantly during the $4 \mathrm{yr}$ period from 1988 to 1991 and then declined significantly during the early 1990 s before increasing towards the end of the study in 1996. This pattern of temporal variability is consistent with the findings of Brown et al. (1995) and suggests that there is significant aperiodic variability in the demographic structure of the EAGVS that migrates each year along the east coast of Australia. The early 1990s comprise the most anomalous series of ENSO (El Niño-Southern Oscillation) events this century (Wang 1995) and such ocean-climate effects might be implicated in the long-term temporal variability evident in the seasonal Hervey Bay population (Fig. 2a). The ecological link with humpback migratory dynamics is unknown but could be a function of the complex relationship between climate, sea-ice extent and krill productivity in Antarctic waters (Loeb et al. 1997). 
The trend in temporal variability of the seasonal humpback abundance in Hervey Bay is consistent with findings from a 14 yr (1982 to 1996) aerial surveillance study of sightings of EAGVS overwintering in GBR waters (Chaloupka \& Osmond 1999). The relative abundance index for overwintering EAGVS humpbacks from Chaloupka \& Osmond (1999) is compared with the CJS estimates of seasonal abundance in Hervey Bay for the 9 yr period between 1988 and 1996 (Fig. 2b). The 2 seasonal abundance profiles derived from different and independent methods and data reflect similar temporal and growth trends providing confidence in the reduced form CJS model used in this study to estimate absolute abundance.

\section{Population recovery trend}

Chittleborough (1965) estimated that the entire Group V humpback stock was reduced from ca 10000 in the pre-whaling period (1935 to 1939) to ca 500 individuals in 1962 . It was estimated that 8000 EAGVS humpbacks were caught in Australian coastal fisheries (1952 to 1962) while $>12000$ Group V humpbacks were caught in pelagic fisheries operating in Antarctic waters between 1949 and 1962 (Chittleborough 1965) - many of these would have been EAGVS humpbacks. Despite being reduced to near extinction in the 1960s, the EAGVS has shown no evidence of any major loss of genetic diversity (Baker et al. 1993) and is undergoing significant population recovery.

The mean ( $9 \mathrm{yr}$ ) seasonal abundance of humpbacks in Hervey Bay derived in the current study from 1000 bootstrap samplings of the abundance estimates $\left(N_{i}\right.$ in Table 1) was 855 (95\% empirical percentile CI: 750 to 936), which suggests a significant increase since the end of commercial whaling in 1962. Clearly the Group $V$ humpback stock is recovering at a slow but steady rate. The seasonal abundance of EAGVS humpbacks in Hervey Bay was estimated to be increasing at $6 \%$ pa. However, the growth or recovery rate was not constant over the 9 yr study (1988 to 1996) but was interval-specific. For instance, the estimated rate over the 4 yr period (1988 to 1991) was $15 \% \mathrm{yr}^{-1}$ but over the next 4 yr period (1991 to 1994) it was $-6 \%$. On the other hand, the long-term 9 yr mean bootstrap estimate was $6.3 \%$ (95\% CI: 2 to $11 \%$ ), which emphasises why long-term studies are needed to reliably estimate trends in humpback abundance and temporal variability.

Paterson et al. (1994) suggested that the EAGVS has increased rapidly since the 1980 s with a sustained annual growth rate of $12 \% \mathrm{yr}^{-1}(95 \% \mathrm{CI}: 10$ to $14 \%)$. This estimate was derived from a program of shorebased observations of humpbacks passing northward along the east Australian coast prior to entering sGBR waters. Chaloupka \& Osmond (1999) suggested from a long-term aerial surveillance study of the frequency of humpback sightings in GBR waters that the EAGVS increased between 1982 to 1996 at $4 \% \mathrm{yr}^{-1}$ (95\% CI: 2 to $6 \%$, which is much lower than $12 \% \mathrm{yr}^{-1}$ suggested by Paterson et al. (1994) but consistent with the recovery rate estimated over the same sampling period for the seasonal population in Hervey Bay (see Fig. 2b).

Chittleborough (1965) estimated that the intrinsic rate of increase for both the Group IV and V stocks was $4.6 \%$ (range: 1 to $8 \%$ ) assuming no density-dependent effects. A sustained mean annual population growth rate $>7 \%$ $\mathrm{yr}^{-1}$ seems demographically implausible given the range of birth and mortality rates estimated for northern and southern hemisphere humpback stocks (Chittleborough 1965, Volgenau et al. 1995, Barlow \& Clapham 1997. Chaloupka \& Osmond 1999).

\section{Survival probability estimate}

The resight of a humpback during a sampling period $t+1$ that was sighted during sampling period $t$ depends on 3 probabilities: (1) the probability of surviving from. period $t$ to period $t+1$, (2) the probability of being present in the study site during period $t+1$ given that it is still alive, and (3) the probability of being resighted in the study site during period $t+1$ given that it is both still alive and also present in the study site. Few studies distinguish between sources (2) and (3) and therefore confound temporary emigration (if it occurs) with resight likelihood giving biased estimates of survival. All 3 probabilities were estimated separately in the current study using a seasonally sequential 2 -site robust sampling design with estimators to account for the presence of temporary emigration (Kendall et al. 1997).

The robust CJS survival probability estimate for post-yearling EAGVS humpbacks was estimated in the current study at $0.966(95 \% \mathrm{CI}: 0.87$ to 1.0$)$. Survival was high and constant over the study period while resight likelihood was time-varying. There was no evidence over the 4 yr sampling period (1993 to 1996) of any significant random or Markovian temporary emigration that assumes resight likelihood in period $t$ is dependent on resight likelihood in period $t-1$ (Table 2). However, this methodology cannot account for the presence (if it exists) of more complex forms of temporary emigration such as resight likelihood in period $t$ being dependent on say resight likelihood in period $t-5$ (i.e. 5 yr quasi-periodicity), which is quite possible for the EAGVS (Brown et al. 1995). Much longer-term mark-resight studies of the EAGVS are needed to address this important issue further.

There have been very few studies that have presented estimates of humpback survivorship. Chittle- 
borough (1965) used age-specific catch-per-unit-effort and linear regression (OLS) to estimate mean annual sex-specific survival probabilities for the Group V stock and the Group IV stock that migrates along the west Australian coast. This enumeration method estimates the probability of remaining available in the sampling area for capture (or return rate) rather than survival because capture is confounded with survival unless capture probability $p=1$. If capture probability is $<1$ then return rates are biased and underestimate true survival. The Group $V$ data were inadequate for any statistical analysis (Chittleborough 1965) but the Group IV data were suitable assuming $\mathrm{p}=1$. Chittleborough (1965) estimated mean return rates between 1949 and 1961 at 0.92 (95\% CI: 0.74 to 1.15 ) for male and 0.92 (95\% CI: 0.76 to 1.10 ) for female Group IV humpbacks.

Neither of the OLS models actually fitted the data because of data anomalies such as measurement error and inter-annual variability (see Chittleborough 1965) giving biased estimates of return rate. A reanalysis here of these data using robust linear regression models (L1 estimator, Judge et al. 1985) that fit the data well estimated Group IV return rates at 0.91 (95\% CI: 0.88 to 0.95 ) for males and 0.86 (95\% CI: 0.79 to 0.94 ) for females. It is doubtful whether there is any significant sex-specific difference in these high return rates that probably underestimate survival probabilities for this stock. This is especially so for female humpbacks that are likely to skip migration in some years (Brown et al. 1995, Craig \& Herman 1997), ensuring that capture probability $<1$ and in fact confounding capture with temporary emigration.

Buckland (1990) used a cohort-based CJS approach to estimate mean annual post-yearling survival probability between 1976 and 1984 for WNAS humpbacks in the Gulf of Maine feeding ground at 0.951 (95\% CI: 0.93 to 0.97). Barlow \& Clapham (1997) used the same statistical procedure and Gulf of Maine feeding ground data as Buckland (1990) to estimate the mean annual female survival probability between 1979 and 1991 at 0.96 (95\% Cl: 0.94 to 0.98). Again there is little evidence for any sex-specific difference in survival. The rather precise survival estimates for the Gulf of Maine WNA substock are due to the small population size and high resight likelihood coupled with the deletion of anomalous estimates (Buckland 1990).

Clearly, post-yearling humpback survival probabilities are high and show no evidence of any significant inter-annual variability or stock- or sex-specific differences (WNAS: Buckland 1990, Barlow \& Clapham 1997; EAGVS and Group IV: current study). High $(>0.90)$ and constant adult survival is a common characteristic of large mammal species (Gaillard et al. 1998), suggesting that it is environmentally induced variability in female migration and juvenile recruitment that are the demographic factors significantly influencing humpback population dynamics.

\section{Management implications}

Associated with the EAGVS population recovery over the last 10 yr has been an increasing demand for commercial whale-watching opportunities (Chaloupka $1990,1996)$. Clearly the EAGVS is recovering but at a slow and variable rate. Based on the CJS abundance estimates in the current study it is unlikely that the Group V stock has increased to more than $25 \%$ of the pre-whaling stock assessment of $>10000$ post-yearlings. There is no basis for relaxing existing regulatory mechanisms at this stage for non-consumptive use of EAGVS humpbacks in Queensland waters until a better understanding of population dynamics has been gained and the risks of whale-watching activities on population viability have been adequately assessed.

Acknowledgements. This work was funded by the PWF and supplemented by grants from the Queensland Environmental Protection Agency. Field assistance was provided by P. Naessig, P. Forestell, C. Jenner, M. Nicole-Jenner, B. Lagerquist, G. Krutzikowsky, E. Brown and numerous PWF interns. We thank R. Cormack for providing GLIM code and sound statistical advise over many years on capture-recapture modelling. We thank S. Baker, E. Brown, M. Donoghue, P. Forestell and C. Limpus for helpful comments on the manuscript.

\section{LITERATURE CITED}

Baker CS, Herman LM, Perry A, Lawton WS, Straley JM, Wolman AA, Kaufman GD, Winn HE, Hall JD, Reinke JM, Ostman J (1.986) Migratory movement and population structure of humpback whales (Megaptera novaeangliae) in the central and eastern North Pacific. Mar Ecol Prog Ser 31:105-119

Baker CS, Perry A, Bannister JL, Weinrich MT, Abernethy RB, Calambokidis J, Lien J, Lambertsen RH, Urban Ramirez J, Vasquez O, Clapham PJ, Alling A, O'Brien SJ, Palumbi SR (1993) Abundant mitochondrial DNA variation and worldwide population structure in humpback whales. Proc Natl Acad Sci USA 90:8239-8243

Barlow J, Clapham PJ (1997) A new birth-interval approach to estumating demographic parameters of humpback whales. Ecology 78:535-546

Brown MR, Corkeron PJ, Hale PT, Schultz KW, Bryden MM (1995) Evidence for a sex-segregated migration in the humpback whale (Megaptera novaeangliae). Proc R Soc Lond Ser B 259:229-234

Buckland ST (1990) Estimation of survival rates from sightings of individually identifiable whales. Rep Int Whal Commn (Special Issue) 1.2:149-153

Burnham KP, Anderson DR, White GC, Brownie C, Pollock $\mathrm{KH}$ (1987) Design and analysis methods for fish survival experiments based on release-recapture. Am Fish Soc Monogr 5:1-437 
Burnham KP, White GC, Anderson DR (1995) Model selection strategy in the analysis of capture-recapture data. Biometrics 51:888-898

Carlson CA, Mayo CA, Whitehead H (1990) Changes in the ventral fluke pattern of the humpback whale and its effect on matching: evaluation of its significance to photo-identification research. Rep Int Whal Commn (Special Issue) 12: 105-112

Chaloupka M (1990) A policy model for regulation of the Hervey Bay commercial whale-watching industry. Internal Policy Report (February 1990), Queensland Department of Environment, Brisbane

Chaloupka M (1996) A policy model for the Moreton Bay Marine Park commercial whale-watching industry. Internal Policy Report (December 1996), Queensland Department of Environment, Brisbane

Chaloupka M, Osmond M (1999) Spatial and seasonal distribution of humpback whales in the Great Barrier Reef. In Musick JA (ed) Life in the slow lane: ecology and conservation of long-lived marine animals. Am Fish Soc Symp 23:89-106

Chittleborough RG (1965) Dynamics of two populations of humpback whales, Megaptera novaeangliae (Borowski) Aust J Mar Freshw Res 16:33-128

Clapham PJ, Mayo CA (1987) Reproduction and recruitment of individually identified humpback whales, Megaptera novaeangliae, observed in Massachusetts Bay, 1979-1985. Can J Zool 65:2853-2863

Corkeron P, Brown M, Slade RW, Bryden MM (1994) Humpback whales, Megaptera novaeangliae (Cetacea: Balaenopteridae), in Hervey Bay, Queensland. Wildl Res 21:293-305

Cormack RM (1993) The flexibility of GLIM analyses of multiple recapture or resighting data. In: Lebreton JD, North PM (eds) Marked individuals in the study of bird populations. Birkhauser Verlag, Basel, p 39-49

Craig AS, Herman L (1997) Sex differences in the site fidelity and migration of humpback whales (Megaptera novaeangliae) to the Hawaiian Islands. Can J Zool 75:1923-1933

Efron B, Tibshirani R (1986) Bootstrap methods for standard errors, confidence intervals, and other measures of statistical accuracy. Stat Sci 1:54-77

Fleiss JL (1981) Statistical methods for rates and proportions 2nd edn. Wiley and Sons, New York

Gaillard JM, Festa-Bianchet M, Yoccoz NG (1998) Population dynamics of large herbivores: variable recruitment with constant adult survival. Trends Ecol Evol 13:58-63

Glockner DA (1983) Determining the sex of humpback whales (Megaptera novaeangliae) in their natural environment. In: Payne R (ed) Communication and behaviour of whales. Westview Press, Boulder, CO, p 447-466

Hammond P (1986) Estimating the size of naturally marked whale populations using capture-recapture techniques. Rep Int Whal Commn (Special Issue) 8:253-282

Judge GG, Griffiths WE, Hill RC, Lutkepohl H, Lee TC (1985)

Editorial responsibility: Otto Kinne (Editor),

Oldendorf/Luhe, Germany
Theory and practice of econometrics, 2nd edn. Wiley and Sons, New York

Katona SK, Beard JA (1990) Population size, migrations, and feeding aggregations of the humpback whale, Megaptera novaeangliae, in the western North Atlantic Ocean. Rep Int Whal Commn (Special Issue) 12:295-305

Kaufman GD, Smultea M, Forestell PH (1987) Use of lateral body pigmentation patterns for photographic identification of east Australian (Area $V$ ) humpback whales. Cetus $7: 5-13$

Kaufman GD, Lagerquist BA, Forestell PH, Osmond M (1993) Humpback whales of Australia: a catalogue of individual whales identified by fluke photographs. Queensland Department of Environment and Heritage, Brisbane

Kaufman GD, Osmond M, Ward AJ, Forestell PH (1990) Photographic documentation of the migratory movement of a humpback whale (Megaptera novaeangliae) between east Australian and Antarctic Area $V$ Rep Int Whal Comn (Special Issue 12):265-267

Kendal.l WL, Nichols JD, Hines JE (1997) Estimating temporary emigration using capture-recapture data with Pollock's robust design. Ecology 78:563-578

Lebreton JD, Burnham KP, Clobert J, Anderson DR (1992) Modeling survival and testing biological hypotheses using marked animals: a unified approach with case studies. Ecol Monogr 62:67-11.8

Link WA, Nichols JD (1994) On the importance of sampling variance to investigations of temporal variation in animal population size. Oikos 69:539-544

Loeb V, Siegel V, Holm-Hansen O. Hewitt R, Fraser RW, Trivelpiece $W$, Trivelpiece S (1997) Effects of sea-ice extent and krill or salp dominance on the Antarctic food web. Nature 387:897-900

Palsboll PJ, Allen J, Berube M, Clapham PJ, Fedderson TP, Hammond PS, Hudson RR, Jorgensen H, Katona S, Larsen AH, Larsen F, Lien J, Mattila DK, Sigurionsson J, Sears R, Smith T, Sponer R, Stevick P, Olen N (1997) Genetic tagging of humpback whales. Nature 388:767-769

Paterson R, Paterson P, Cato DH (1994) The status of humback whales Megaptera novaeangliae in east Australia thirty years after whaling. Biol Conserv 70:135-142

Pollock KH, Nichols JD, Brownie C, Hines JE (1990) Statistical inference for capture-recapture experiments. Wildl Monogr 107:1-97

Pradel R (1993) Flexibility in survival analysis from recapture data: handling trap-dependence. In: Lebreton JD, North PM (eds) Marked individuals in the study of bird populations. Birkhauser Verlag, Basel, p 29-37

Volgenau L, Kraus SD, Lien J (1995) The impact of entanglement on two substocks of the western North Atlantic humpback whale, Megaptera novaeangliae. Can J Zool 73:1689-1698

Wang B (1995) Interdecadal changes in El Nino onset in the last four decades. J Clim 8:267-285

Subnitted: November 23, 1998; Accepted: March 29, 1999 Proofs received from author(s): July 19, 1999 